\title{
Prevalence of Primary Non-adherence with Insulin and Barriers to Insulin Initiation in Patients with Type 2 Diabetes Mellitus - An Exploratory Study in a Tertiary Care Teaching Public Hospital
}

\author{
Suresh K Sharma, ${ }^{1}$ Ravi Kant, ${ }^{2}$ Sanjay Kalra ${ }^{3}$ and Ravin Bishnoi ${ }^{4}$ \\ 1. College of Nursing, All India Institute of Medical Sciences, Rishikesh, Uttarakhand, India; 2. Division of Diabetes and Metabolism, All India Institute of \\ Medical Sciences, Rishikesh, Uttarakhand, India; 3. Department of Endocrinology, Bharti Research Institute of Diabetes and Endocrinology (BRIDE), Karnal, \\ Haryana, India; 4. Division of Diabetes and Metabolism, All India Institute of Medical Sciences, Rishikesh, Uttarakhand, India
}

DOl: https://doi.org/10.17925/EE.2020.16.2.143

\begin{abstract}
ntroduction: There is a paucity of data analysing the reasons for primary non-adherence following first prescription of insulin among patients with uncontrolled type 2 diabetes mellitus (T2DM) in India. To address this, and to attempt to understand these reasons, an exploratory study was undertaken to assess the prevalence of primary non-adherence with insulin and barriers to insulin initiation in these patients. Methods: Study participants were randomly selected from patients with T2DM who visited the diabetes clinic of a tertiary care teaching public hospital in Rishikesh, Uttarakhand, India, and were prescribed insulin for the first time in last 2-year period. All participants were evaluated for history of primary non-adherence, and those who were non-adherent were subsequently interviewed face-to-face using a modified, validated semi-structured questionnaire to identify the reasons for primary non-adherence. A focused group discussion was also conducted with eight physicians to elicit their views about reasons for primary non-adherence with insulin. Results: A total of 225 patients were identified and interviewed; of these, 105 were identified with a history of primary non-adherence and underwent a subsequent face-to-face interview. There was a high prevalence of primary non-adherence with insulin among the participants of this study. The main reasons for non-adherence were low self-efficacy, doubt about clinical benefits of insulin, fear of hypoglycaemia, needle phobia, unaffordability of insulin and blood glucose monitoring device, strong faith in alternative medicines and mythical ideologies, and fears of insulin being addictive and that it may cause rapid aging. Conclusion: With the high prevalence of primary non-adherence, and the multitude of reasons for this, it is clear that we need to eliminate these barriers to treatment. Thus, provision of dedicated diabetes educators in each diabetes clinic and availability of cost-effective insulin and blood glucose monitoring devices for the underprivileged population are key to achieve this.
\end{abstract}

\section{Keywords}

Insulin, diabetes, medication, non-adherence, self-efficacy

Disclosures: Suresh K Sharma, Ravi Kant, Sanjay Kalra and Ravin Bishnoi have no financial or non-financial relationships or activities to declare in relation to this article. Sanjay Kalra is a member of the journal's Editorial Board. Review Process: Double-blind peer review.

Compliance with Ethics: The research project was approved by Institutional Ethical Committee, AllMS, Rishikesh, India, and informed written consent was obtained from each participant for voluntary participation in the study.

Data Availability: The datasets during and/or analysed during the current study are available from the corresponding author on reasonable request.

Authorship: The named authors meet the International Committee

of Medical Journal Editors (ICMJE) criteria for authorship of this

manuscript, take responsibility for the integrity of the work as a whole,

and have given final approval for the version to be published.

Access: This article is freely accessible at touchENDOCRINOLOGY.com (C) Touch Medical Media 2020.

Received: 11 March 2020

Accepted: 20 April 2020

Published Online: 26 August 2020

Citation: European Endocrinology. 2020;16(2):143-7

Corresponding Author: Suresh K Sharma, College of Nursing, All India Institute of Medical Sciences, Rishikesh, 249203 Uttarakhand, India. E: sk.aiims17@gmail.com

Support: No funding was received in the publication of this article.
The management of type 2 diabetes mellitus (T2DM) involves multifactorial strategies that include diet management, exercise, glucose monitoring, anti-obesity measures, intake of oral antihyperglycaemic agents and, in some cases, insulin administration. Despite the use of multiple oral antihyperglycaemic drugs at maximum dose, some patients are unable to maintain glycaemic control and are recommended to initiate insulin. ${ }^{1-2}$ While insulin is reported to be one of the most reliable therapeutic options for the management of diabetes, some studies have reported that patients have reservations about starting insulin administration due to misconceptions regarding insulin risk, injection phobia, fear of weight gain, hypoglycaemia concerns, negative impact on social life and job, poor health literacy, low self-efficacy and healthcare providers' inadequacy..$^{3-4}$ There are also a few barriers relating to healthcare professionals, such as lack of knowledge, training and experience; language barriers; concern over the risk of hypoglycaemia and weight gain; perceived patient resistance resulting from fear of injections; and presumed patient non-adherence. In addition, healthcare system factors also contribute to patient primary non-adherence with insulin, such as lack of resources (e.g., staff and materials), continuity of care, primary care providers' high workload and time constraints, and ambiguity of roles in the primary care team. ${ }^{5}$ The possible solutions to overcome the barriers of insulin initiation could lie in multidisciplinary teams and an integrated system for insulin initiation programmes. The involvement of non-governmental organisations through provision of training and education for both patients and healthcare workers, could also be key, along with reinforcing healthcare workers' skills and knowledge through training and workshops. Healthcare professionals 
should also consider the use of electronic decision-support tools and adoption of technology like prefilled insulin pens etc. ${ }^{5}$

India is the world capital of diabetes with more than 72 million people currently diagnosed with diabetes.6,7 This figure alarms healthcare providers and encourages the emergence of interventions to improve patients' adherence with diabetes management, with a special focus on insulin adherence. However, most of the available data related to barriers of insulin initiation are from other countries. India is demographically, culturally, and socio-economically very different from these counties. Therefore, considering the paucity of literature regarding barriers to insulin initiation in an Indian scenario, this exploratory study aimed to assess the prevalence of primary non-adherence and barriers to insulin initiation from patients' and physicians' perspectives in this region.

\section{Materials and methods}

This exploratory study with a parallel convergent design was conducted in the diabetes clinic of a tertiary care teaching hospital at Rishikesh, Uttarakhand, India. The clinic's medical database was used to enrol patients with T2DM, who were prescribed insulin for the first time in last 2 years (March 2017-April 2019). The research project was approved by the Institutional Ethical Committee, AllMS, Rishikesh, India, and informed written consent was obtained from each participant for voluntary participation in the study.

The two terms frequently used in the present study are operationally defined; i) primary non-adherence: patients' non-adherence behaviour with initiation of insulin, when prescribed for the first time by a physician; and ii) self-efficacy: patients' knowledge and skills about insulin administration.

The sample size required was estimated by using formula: ${ }^{*}$ *

$$
n=\frac{\left(z_{1-a / 2}\right)^{2}(p)(q)}{d^{2}}
$$

$*\left(Z_{1-a / 2}\right)^{2}=$ critical value and a standard value for the 95\% Cl, i.e. 1.96; $p=$ prevalence of primary non-adherence $(29.9 \%)=0.30 ; q=1-p=1-0.30=0.70 ; d^{2}=$ margin of error or precision is $6 \%=0.06$

Assuming $29.9 \%$ prevalence of primary non-adherence among patients with uncontrolled T2DM, ${ }^{9}$ with an absolute margin of error fixed as $6 \%$ and a confidence interval (Cl) of $95 \%$, the minimum estimated sample size was 224 participants. With an assumed non-response rate of $35 \%$, a total sample size of 300 was considered for the present study. Patients who are diagnosed with T2DM and prescribed insulin for the first time during the last 2 years were included in the present study. Patients with T2DM receiving oral antihyperglycaemic drugs and who were not willing to participate in study were excluded.

A sampling frame of patients with T2DM who were prescribed insulin therapy for the first time during the last 2 years was obtained from the diabetes clinic. Participants were selected through simple random sampling and were contacted by telephone for the follow-up. Exclusion criteria were significant cognitive deficits, psychiatric illness and visual impairment limiting insulin self-administration. Selected participants with T2DM were interviewed to collect sociodemographic data and history of primary non-adherence with first-time insulin prescription. Subsequent face-to-face interviews were conducted with participants who had a history of primary non-adherence, using a semi-structured questionnaire based on an existing valid and reliable instrument 'The Barriers to Insulin Treatment Questionnaire'.10 This instrument was modified to make it more suitable for an Indian scenario; further, it was converted into a semi-structured format to make it open and flexible to obtain a wider range of responses. Content validity of the modified questionnaire was ensured through inputs from five experts in the field of diabetes care.

Furthermore, eight purposely selected physicians from the selected institute (consultants [ $n=4]$ and senior resident doctors $[n=4]$ ), who are involved in care of diabetes, were enrolled to conduct a focused group discussion. The focused group discussion was conducted with four main questions: i) what are your criteria for prescribing insulin to patients with T2DM; ii) in your experience, what average percentage of patients refuse insulin when advised first time; iii) what is your opinion about barriers to insulin initiation related to patients, physicians and the healthcare system; and iv) do you believe that insulin is the last resort for the management of diabetes? Focused group discussion was video recorded and field notes were taken, which were validated by two independent experts to confirm the validity and trustworthiness of the data.

Data were coded, entered into Microsoft Excel sheets and the Statistical Package for Social Science (SPSS 21.0) was used for statistical analysis. Descriptive and inferential statistics were used for analysis of quantitative data, where $95 \% \mathrm{Cl}$ was also computed for the proportions of participants who expressed delayed initiation of insulin and identified barriers of insulin initiation. Qualitative thematic analysis was performed to draw themes and categories from the transcribed and translated content of focused group discussion.

\section{Results}

\section{Demographic characteristics of patients}

A total of 300 patients were selected through simple random sampling technique, and were contacted by telephone for follow-up. Out of these, 236 patients attended a follow-up visit (78.7\% response rate). A further 11 patients with significant cognitive deficits, psychiatric illness and visual impairment, limiting insulin self-administration, were excluded, leaving 225 patients who met the study eligibility criteria and comprised the study population. The mean age of participants was $54.9 \pm 12.9$ years (range 25-84 years), the majority of them were rural dwellers and nearly half of them were males $(n=109 ; 48.4 \%)$. Less than half of the participants were illiterate $(n=88 ; 39.1 \%)$ and nearly half of them $(47.8 \%)$ had education up to secondary level. A significant proportion of participants (63.2\%) had a low monthly family income (i.e., only ₹1000-5000/month) (Table 1). The mean glycated haemoglobin ( $\mathrm{HbA} 1 \mathrm{C}$ ) of participants was $8.7 \%$, and all of them were on combination therapy of oral antidiabetic drugs, comprising maximum tolerable dose of metformin and glimepiride, at the time they were prescribed insulin.

\section{Barriers to insulin initiation experienced by patients}

A total 225 participants were interviewed face-to-face and it was found that 137 (60.9\%) had experienced diabetes for 4 years or more, followed by 28 (12.4\%) who had experienced diabetes for 3-4 years, 30 (13.3\%) $1-2$ years and the rest $<1$ year. Almost half of the participants (105; 46.7\%; 95\% Cl 40.0-53.4) delayed initiation of insulin therapy, while $120(53.3 \%)$ initiated insulin treatment immediately after their doctor's first prescription. The participants who delayed the insulin initiation were interviewed for the barriers to insulin initiation as illustrated in (Table 2).

The participants' experiences were collected through in-depth face-to-face interviews using a semi-structured questionnaire. The responses received from participants regarding barriers to insulin initiation were categorised in six domains: i) personal barriers; ii) financial 
Table 1: Socio-demographic profile of participants $(\mathrm{N}=225)$

\begin{tabular}{|l|l|}
\hline Socio-demographic profile & n (\%) \\
\hline Age in years & \\
\hline $25-40$ & $32(14.2)$ \\
$41-55$ & $80(35.6)$ \\
$56-75$ & $90(40.0)$ \\
$>75$ & $23(10.2)$ \\
\hline Gender & \\
\hline Female & $116(51.6)$ \\
Male & $109(48.4)$ \\
\hline Place of residence & \\
\hline Rural & $167(74.2)$ \\
Urban & $58(25.8)$ \\
\hline Educational status & \\
\hline Illiterate & $88(39.1)$ \\
\hline Primary & $21(9.3)$ \\
Secondary & $82(36.4)$ \\
Graduate and above & $34(15.1)$ \\
\hline Monthly family income & \\
\hline ₹1,000-5,000 & $136(60.4)$ \\
₹5,001-10,000 & $74(32.9)$ \\
\hline$>$ ₹10,000 & $15(6.7)$ \\
\hline
\end{tabular}

barriers; iii) family-related barriers; iv) side effect-related barriers; v) myths about insulin; and vi) occupation-related barriers. The major barriers to insulin initiation were lack of knowledge about routes of insulin administration ( $n=63 ; 60.0 \% ; 95 \% \mathrm{Cl}$ 50.6-69.4), insulin dose adjustment ( $n=62 ; 59.0 \% ; 95 \%$ Cl:49.6-68.5), injection site rotation ( $n=49$; 46.7\%; 95\% Cl 37.1-56.2), and doubt about the clinical benefits of insulin $(n=55 ; 52.4 \%$; 95\% Cl:42.8-61.9). Other important barriers were fear of hypoglycaemia ( $n=49 ; 46.7 \% ; 95 \% \mathrm{Cl} 37.1-56.2$ ), lack of family support for insulin administration ( $n=37 ; 35.2 \% ; 95 \% \mathrm{Cl} 26.1-44.4)$, needle phobia $(n=37 ; 35.2 \% ; 95 \% \mathrm{Cl} 26.1-44.4)$, cost of insulin $(n=37 ; 35.2 \% ; 95 \% \mathrm{Cl}$ 26.1-44.4), cost of blood glucose monitoring ( $n=32 ; 30.5 \%$; $95 \% \mathrm{Cl}$ 21.7-39.3), and preference of alternative system of medicines over insulin ( $n=32 ; 30.5 \% ; 95 \% \mathrm{Cl}$ 21.7-39.3). Participants also held some myths about insulin, such as insulin would change their life $(n=35 ; 33.3 \%$; $95 \% \mathrm{Cl} 24.3-42.4)$, insulin is addictive ( $n=32 ; 30.5 \%$; $95 \% \mathrm{Cl} 21.7-39.3)$, insulin may cause rapid aging ( $n=26 ; 24.8 \%$; $95 \% \mathrm{Cl} 16.5-33.0)$, insulin may decrease sexual desire $(n=4 ; 3.8 \%$; $95 \% \mathrm{Cl} 0.1-7.5)$, or may cause weight gain $(n=4 ; 3.8 \%$; $95 \% \mathrm{Cl} 0.1-7.5)$.

\section{Demographic characteristics of physicians}

The demographic profile of the eight physicians shows that the majority of physicians $(n=7)$ were $30-45$ years old and two female. Out of eight physicians, four were consultants and the other four were senior resident doctors. Their experience of working with diabetes patients varied between $2-10$ years.

Barriers to insulin initiation perceived by physicians The detailed data collected from physicians through focused group discussion were analysed using a thematic analysis and these themes are presented under four main categories as mentioned below.

\section{Theme 1 - criteria followed for prescribing insulin}

The majority of the physicians prescribed insulin when patients had: i) $\mathrm{HbA} 1 \mathrm{C}>9 \%$, fasting blood glucose $>126 \mathrm{mg} / \mathrm{dL}$, post-prandial blood glucose $>200 \mathrm{mg} / \mathrm{dL}$ and body mass index $>24 \mathrm{~kg} / \mathrm{cm}^{2}$; ii) HbA1c 8-9\%,
Table 2: Barriers relating to primary non-adherence of insulin therapy $\left(n=105^{*}\right)$

\begin{tabular}{|c|c|c|}
\hline Barriers of insulin initiation & $\mathrm{n}(\%)$ & $95 \% \mathrm{Cl}$ \\
\hline \multicolumn{3}{|l|}{ Personal barriers } \\
\hline $\begin{array}{l}\text { Lack of knowledge about route of administration } \\
\text { Lack of knowledge about dose adjustment } \\
\text { Doubts about clinical benefits } \\
\text { Lack of knowledge about site rotation } \\
\text { Needle phobia due to fear of pain } \\
\text { Preference of alternative systems of medicines } \\
\text { over insulin } \\
\text { Causal attitude towards insulin initiation }\end{array}$ & $\begin{array}{l}63(60.0) \\
62(59.0) \\
55(52.4) \\
49(46.7) \\
37(35.2) \\
32(30.5) \\
21(20.0)\end{array}$ & $\begin{array}{l}50.6-69.4 \\
49.6-68.5 \\
42.8-61.9 \\
37.1-56.2 \\
26.1-44.4 \\
21.7-39.3 \\
12.4-27.7\end{array}$ \\
\hline \multicolumn{3}{|l|}{ Financial barriers } \\
\hline $\begin{array}{l}\text { High cost of insulin } \\
\text { High cost of monitoring/administration devices } \\
\text { Lack of storage facilities e.g. refrigerator }\end{array}$ & $\begin{array}{l}37(35.2) \\
32(30.5) \\
17(16.2)\end{array}$ & $\begin{array}{l}26.1-44.4 \\
21.7-39.3 \\
9.1-23.2\end{array}$ \\
\hline \multicolumn{3}{|l|}{ Family-related barriers } \\
\hline $\begin{array}{l}\text { Lack family support for insulin administration } \\
\text { Stigma among family and friends } \\
\text { Previous history of insulin administration-related } \\
\text { complications in family }\end{array}$ & $\begin{array}{l}37(35.2) \\
10(9.5) \\
7(6.7)\end{array}$ & $\begin{array}{l}26.1-44.4 \\
3.9-15.1 \\
1.9-11.4\end{array}$ \\
\hline \multicolumn{3}{|l|}{ Side effect-related barriers } \\
\hline $\begin{array}{l}\text { Fear of hypoglycaemia } \\
\text { Breakdown of fat tissue } \\
\text { Allergic reactions }\end{array}$ & $\begin{array}{l}49(46.7) \\
16(15.2) \\
4(3.8)\end{array}$ & $\begin{array}{l}37.1-56.2 \\
8.4-22.1 \\
0.1-7.5\end{array}$ \\
\hline \multicolumn{3}{|l|}{ Myths about insulin } \\
\hline $\begin{array}{l}\text { Insulin means my life will change } \\
\text { Insulin is addictive } \\
\text { May cause rapid aging } \\
\text { Decline in sexual desire } \\
\text { Weight gain }\end{array}$ & $\begin{array}{l}35(33.3) \\
32(30.5) \\
26(24.8) \\
4(3.8) \\
4(3.8)\end{array}$ & $\begin{array}{l}24.3-42.4 \\
21.7-39.3 \\
16.5-33.0 \\
0.1-7.5 \\
0.1-7.5\end{array}$ \\
\hline \multicolumn{3}{|l|}{ Occupation-related barriers } \\
\hline $\begin{array}{l}\text { Lack of rest in work hours } \\
\text { Prolonged duty hours } \\
\text { Irregular meal pattern during work hours } \\
\text { Absence of privacy while administering insulin } \\
\text { Occupation involving long hours of travelling }\end{array}$ & $\begin{array}{l}19(18.1) \\
17(16.2) \\
13(12.4) \\
5(4.8) \\
4(3.8)\end{array}$ & $\begin{array}{l}10.7-25.5 \\
9.1-23.2 \\
6.1-18.7 \\
0.7-8.8 \\
0.1-7.5\end{array}$ \\
\hline
\end{tabular}

*Multiple responses by each participant.

$\mathrm{Cl}=$ confidence interval.

fasting blood glucose $>200 \mathrm{mg} / \mathrm{dL}$ and post-prandial blood glucose $>300 \mathrm{mg} / \mathrm{dL}$. They also prescribed insulin for patients with poor glycaemic control despite maximal dose of oral antihyperglycaemic agents and patients presenting with complications of diabetes such as nephropathy, chronic kidney disease, diabetic retinopathy, etc.

\section{Theme 2 - average percentage of patients who refuse to initiate insulin}

Physicians treated the bulk of patients with diabetes with insulin, and from their experience, the majority of physicians stated that $50-60 \%$ of patients refuse insulin therapy, while two of them mentioned that only $10-20 \%$ patients refuse insulin therapy.

\section{Theme 3 - perceived barriers to insulin initiation}

Primary non-adherence with insulin is a multifactorial phenomenon and barriers expressed by the physicians are grouped under three headings: i) patient-related barriers; ii) system-related barriers and iii) physician-related barriers, which are summarised in Table 3. The majority of the physicians expressed that the cost of insulin, fear of injection, lack of knowledge and self-efficacy of insulin administration, 
Table 3: Barriers of insulin initiation perceived by the physicians $(n=8)$

\begin{tabular}{l} 
Patient-related barriers \\
Inability to afford insulin price \\
Inability to afford blood glucose monitoring device \\
Fear of injection pain \\
Fear of hypoglycaemia \\
Lack of knowledge and self-efficacy of insulin administration \\
Lack of patient's family support in insulin administration \\
Patient's fear of having to continue insulin for lifetime \\
Difficulty in maintaining compliance of dosing interval \\
Difficulty in regular blood glucose monitoring \\
Lack of storage facilities for insulin at home \\
\hline Healthcare system-related barriers \\
\hline Absence of diabetes educator support in hospitals \\
Lack of free insulin availability for low-income patients \\
Heavy workload for physicians \\
\hline Physician-related barriers \\
\hline Negative attitude towards insulin initiation among primary physicians \\
Lack of training, motivation and confidence among primary physicians \\
Physicians fear for patient's poor compliance and side effects of \\
insulin administration \\
Lack of time with physicians to educate and train them for insulin administration \\
\hline
\end{tabular}

and fear of hypoglycaemia, are the main patient-related barriers; lack of diabetes educators' support in hospitals and lack of training, motivation and confidence among primary physicians, were the main system and physician-related possible barriers to insulin initiation.

Theme 4 - insulin the 'last resort' for diabetes management The majority of physicians $(6 / 8 ; 75.0 \%)$ believed that insulin is not the last resort for diabetes, while one of them mentioned that 'I shall choose it as the last resort because of patients' poor knowledge and skills of compliance, and there are no newer therapies yet approved to cure diabetes mellitus.' and another mentioned that 'insulin resistance goes on increasing with time. So, patients require insulin therapy in the end.'

\section{Discussion}

The present study reported a high rate of delayed initiation of insulin therapy among patients with uncontrolled T2DM $(46.7 \%$; 95\% Cl 40.0-53.4). A recent study by Hosomura et al., also reported that $29.9 \%$ of patients refused insulin therapy when prescribed first time, and refusal rate was high among those with poorly controlled diabetes ( $\mathrm{HB} 1 \mathrm{AC} \geq 9 \%$ ). Of the patients that declined insulin, 38\% of them eventually initiated treatment, but after a mean time of 790 days. ${ }^{9}$ This is a very alarming finding because during this period of poorly controlled diabetes, patients may develop several crippling or life-threatening complications. Furthermore, a recent, large, multicentre study from India reported that in a 9-month period, 64.35\% patients with T2DM moved back from insulin to oral antihyperglycaemic drugs, primarily due to hypoglycaemic episodes (25.9\%), stress (17.1\%), fear of injection (10.3\%) and cost of insulin (7.4\%). ${ }^{11}$

The refusal or delaying of insulin initiation is a multifactorial phenomenon. A systematic review of 19 studies, mostly from Western world, except one from Pakistan, found that the major patient-related barrier to insulin initiation was fear of injection. Physicians' lack of knowledge, training and experience of timely initiation of insulin, language barrier between physician and patient, physician's concern for the risk of hypoglycaemia and weight gain, lack of resources, (e.g. staff and material), lack of continuity of care, high workload, and ambiguity of roles in the primary care team were other barriers highlighted in this review. ${ }^{5}$ Other studies from Western countries have identified major barriers to insulin initiation, including perception of insulin as last resort, use of insulin as evidence of a personal failure to appropriately self-manage diabetes, concerns about long-term complications and side effects (especially hypoglycaemia), cost of insulin, inconvenience and interference with social and work activities and relationships, fear of needles/pain of insulin injection, weight gain, loss of independence, depression, the perception of insulin as a threat or punishment, the failure to see health benefits of insulin therapy, lack of social support and concerns about social stigma and discrimination. ${ }^{12-19}$ Additionally, myths surrounding insulin that lead to delayed initiation have also been reported, these include fear that it may cause blindness, renal failure, amputations, heart attacks, strokes or early death. ${ }^{3}$

The present study identified that the major barriers of insulin initiation are patients' lack of knowledge about routes of insulin administration; insulin dose adjustment and injection site rotation; doubt on clinical benefits of insulin; fear of hypoglycaemia; cost of insulin; lack of family support; needle phobia; preference of alternative systems of medicine; and myths, such as the interference of insulin with every-day life, the fear that it is addictive and that it will cause rapid aging. It is pertinent to discuss that our study is reporting some unique barriers contributing to delayed insulin initiation, which are the patient's lack of knowledge about routes of insulin administration, insulin dose adjustment and injection site rotation; this is believed to be due lack of time with physicians to educate patients, absence of diabetes educators in diabetes clinics, patients' inadequate health literacy and lack of diabetes education literature and resources in local languages for patients' reference. Poor health literacy has been well documented in Indian adults, ${ }^{20}$ which significantly contributes to poor compliance and glycaemic control. 21,22 Non-supportive behaviour of family members is significantly associated with suboptimal adherence with prescribed antidiabetic treatment regimens, ${ }^{-24}$ which was also reported as one of the significant barriers in timely initiation of prescribed insulin in our study. Most of the study participants were rural dwellers and not well-educated, ideally requiring family support in order to understand the dose, frequency and route of administration of insulin.

Furthermore, in the present study, physicians believed that patients' inability to afford insulin, needle phobia, lack of knowledge and self-efficacy of insulin administration, fear of hypoglycaemia, lack of diabetes educators' support and motivation, and lack of confidence in primary physicians are the main barriers contributing to delayed insulin initiation. Indeed, consistent with these physician perceptions, patients reported lack of self-efficacy, fear of hypoglycaemia, needle phobia, high cost of insulin, lack of family support and insulin myths as their main barriers to initiating insulin in a timely manner.

In order to address the reasons for primary non-adherence to insulin therapy, we need to look at the gaps in patient education, in addition to providing support and counselling for self-efficacy-related barriers. ${ }^{4,3,15,24}$ With regard to barriers relating to cost and perceived lack of benefit of insulin, it may be possible to address these with social marketing and the use of modern insulin regimens. ${ }^{24}$ For example, insulin pen devices are widely accepted and are associated with greater adherence, improved outcomes, and lower treatment costs. ${ }^{16}$ Physician training on various aspects of diabetes care can help overcome negative perception barriers to timely initiation of insulin. ${ }^{24}$ Flexibility in the dosing of insulin, ${ }^{4,13}$ enhanced quality of physician-patient communication; ${ }^{25}$ and adequate time spent by the physician, diabetes nurse or diabetes educator to 
make shared diabetes management decisions, ${ }^{16,26-27}$ may also help motivate patients to initiate insulin at the time it is prescribed and adhere to therapy.

\section{Limitations}

The present study was limited to a single tertiary care teaching public hospital and the majority of participants had low levels of education, were rural dwellers and from poor socioeconomic backgrounds. Thus, the sample may not be a true representation of the population from the region. Therefore, readers are advised to take this into consideration with respect to generalising the findings to entire diabetes populations of the region or country.

\section{Conclusion}

Lack of self-efficacy, myths, and cost of insulin were the major reasons identified for primary non-adherence to insulin therapy in the present study population. Therefore, we suggest that each diabetes clinic must have one or more dedicated diabetes educator to address these barriers, as physicians are overloaded and there is very poor health literacy in the country. These barriers to insulin initiation can be addressed through focused, individualised diabetes education and provision of cost-effective insulin and blood glucose monitoring devices for the underprivileged population. $\square$
1. Nyenwe $E A$, Jerkins TW, Umpierrez GE, Kitabchi AE. Management of type 2 diabetes: evolving strategies for the treatment of patients with type 2 diabetes. Metabolism. 2011;60:1-23.

2. Nathan DM, Buse JB, Davidson MB, et al. Management of hyperglycemia in type 2 diabetes: a consensus algorithm for the initiation and adjustment of therapy: a consensus statement from the American Diabetes Association and the 2006:29:1963-72.

3. Karter AJ, Parker MM, Subramanian U, et al. Barriers to insulin initiation: The translating research into action for diabetes initiation: The translating research into action for diabetion

4. Brod M. Alolga SL, Meneghini L. Barriers to initiating insulin in type 2 diabetes patients: Development of a new patient education tool to dress myths, misconceptions and clinica realities. Patient. 2014;7:437-50.

5. Bin rasheed A, Chenoweth I. Barriers that practitioners face when initiating insulin therapy in general practice setting and how they can be overcome. World I Diabetes. 2017;8:28-39.

6. Joshi SR, Parikh RM. India - diabetes capital of the world now heading towards hypertension. J AsSOc Physicians India. 2007;55:323-4.

7. International Diabetes Federation. IDF Diabetes Atlas 9th edition 2019. Available at: www.diabetesatlas.org (accessed 22 April 2020)

8. Sharma SK, Mudgal SK, Thakur K, Gaur R. How to calculate sample size for observational and experimental nursing sample size for observational and experimental nursing
research studies? Natl J Physiol Pharm Pharmacol. 2020:10:1-8.

9. Hosomura N, Malmasi S, Timerman D, et al. Decline of insulin initiation in people with uncontrolled diabetes mellitus. Diabet Med. 2017;34:1599-602

10. Petrak F, Stridde F, Leverkus F, et al. Development and validation of new measure to evaluate psychological resistance to insulin treatment. Diabetes Care. 2007;30:2199-204.

11. Raj P, Panwar D, Jabeen S, Shrivaram VS. A real-world evidence in understanding the barriers and behaviours of insulin therapy among Indian type 2 diabetes mellitus (T2DM) patients. Diabetes. 2018;67(Suppl. 1):884-P.

12. Edelman $\mathrm{S}$, Pettus J. Challenges associated with insulin therapy in type 2 diabetes mellitus. Am J Med. 2014;127 therapy in type 2 .

13. Brod M, Kongsø JH, Lessard S, Christensen TL. Psychological insulin resistance: patient beliefs and implications for diabetes management. Qual Life Res. 2009;18:23-32.

14. Kruger DF, LaRue S, Estepa P. Recognition of and steps to mitigate anxiety and fear of pain in injectable diabetes treatment. Diabetes Metab Syndr Obes. 2015;8:49-56.

15. Philis-Tsimikas A. Initiating basal insulin therapy in type 2 diabetes: practical steps to optimize glycemic control. Am J Med. 2013;126(9 Suppl. 1):S21-7.

16. Campbell RK. Recommendations for improving adherence to type 2 diabetes mellitus therapy--focus on optimizing insulin-based therapy. Am I Manag Care. 2012;18(3 Suppl.):S55-61.

17. Funnell MM. Overcoming barriers to the initiation of insulin therapy. Clin Diabetes. 2007;25:36-8.

18. Ng CJ, Lai PS, Lee YK, et al. Barriers and facilitators to starting $\mathrm{Ng}$ CJ, Lai PS, Lee YK, et al. Barriers and facilitators to starting
insulin in patients with type 2 diabetes: a systematic review. Int J Clin Pract. 2015:69:1050-70
19. Holmes-Truscott E, Skinner TC, Pouwer F, Speight J. Negative appraisals of insulin therapy are common among adults with type 2 diabetes using insulin: Results from Diabetes MILES - Australia cross-sectional survey. Diabet Med. 2015;32:1297-303.

20. D'Cruz AM, Aradhya MRS. Health literacy among Indian adults seeking dental care. Dent Res J (IIfahan). 2013;10:20-4.

21. Gurtoo A, Ap MK. Level of health literacy among type 2 diabetic persons and its relation to glycemic control. J Assoc Physicians India. 2019;67:59-62.

22. Tefera YG, Gebresillassie BM, Emiru YK, et al. Diabetic health literacy and its association with glycemic control among adult patients with type 2 diabetes mellitus attending the outpatient clinic of a university hospital in Ethiopia. PLOS One. 2020;15:e0231291

23. Mayberry LS, Osborn CY. Family support, medication adherence, and glycemic control among adults with type 2 diabetes. Diabetes Care. 2012;35:1239-45.

24. Kalra S, Ghosal S, Shah P. Consensus on bridges for barriers to insulin therapy. J Assoc Physicians India. 2017;65(3 Suppl.):23-30.

25. Marzec LN, Maddox TM. Medication adherence in patients with diabetes and dyslipidemia: associated factors and strategies for improvement. Curr Cardiol Rep. 2013;15:418

26. Karter AJ, Subramanian U, Saha C, et al. Barriers to insulin initiation: the translating research into action for diabetes insulin starts project. Diabetes Care 2010:33:733-5.

27. Frid AH, Kreugel G, Grassi G, et al. New insulin delivery recommendations. Mayo Clin Proc. 2016:91:1231-55. 